\title{
POLYUNSATURATED FATTY ACIDS, PHYTOSTEROLS AND CHOLESTEROL METABOLISM IN THE MEDITERRANEAN DIET
}

\author{
Zdeněk Zadák, Radomír Hyšpler, Alena Tỉchá, Dagmar Solichová, Vladimír Bláha, Bohuslav Melichar
}

Charles University in Prague, Faculty of Medicine and University Hospital in Hradec Králové, Czech Republic: Department of Gerontology and Metabolic Care

Summary: The objective of this work was to review nutritional components of the Mediterranean diet. The Mediterranean diet is not a specific diet plan or diet program but a collection of eating habits that are traditionally followed by the people of the Mediterranean region. There are at least 16 countries bordering the Mediterranean Sea and food habits vary between these countries according to culture, ethnic background and religion. The Mediterranean diet, containing olive oil, fish, fruits and vegetable is associated with a low rate of cardivascular and cancer diseases. This diet is rich in phytosterols, squalene, dietary fibre, antioxidants, phenolic substances and polyunsaturated acids.

Key words: Mediterranean diet; Fatty acid; Squalene; Phytosterols; Vegetable and fish oils

\section{Introduction}

The Mediterranean diet is characterized by high consumption of olive oil, vegetables and fresh fruits. Depending on the particular geographical area, the traditional Mediterranean diet is not only rich in vegetable oil, but also in n-3 long chain polyunsaturated acids (n-3 PUFA), which are present in fish and seafood (4).

The consumption of food rich in monounsaturated fats (olive oil), n-3 polyunsaturated fats (fish oil), dietary fibres, antioxidants and other non/nutrient substances like squalene, olive oil phenolic substances were found to be associated with a lower risk of cardiovascular diseases, myocardial infarction in particular (9). Mortality rates from ischemic heart disease are in table 1. Studies of single protective nutrients are theoretically interesting, but the effect

Tab. 1: Mortality rates from ischemic heart disease (per 100000 males or females) in 1987 (3).

\begin{tabular}{|c|c|c|}
\hline \multirow{2}{*}{ Country } & \multicolumn{3}{|c|}{ Ischemic heart disease } \\
\cline { 2 - 3 } & Males & Females \\
\hline Finland & 386 & 169 \\
\hline Norway & 307 & 123 \\
\hline Ireland & 372 & 169 \\
\hline UK & 340 & 157 \\
\hline Italy & 144 & 65 \\
\hline Spain & 109 & 48 \\
\hline Portugal & 108 & 52 \\
\hline Greece & 132 & 58 \\
\hline
\end{tabular}

or a dietary pattern and protective nutrients synergism cannot be overlooked (6).

The effects of this type of diet include:

- Lipid lowering effect

- Blood pressure lowering effect

- Prevention of atherosclerotic plaque rupture (stabilization of unstable plaque)

- Thrombosis prevention

- Protection against malignant arrhythmias

- Protection against low density lipoproteins (LDL) oxidative modification

- Colon cancer and prostatic cancer prevention

\section{Components of the Mediterranean diet}

The benefits of the Mediterranean pattern of a diet (low incidence of cardiovascular diseases, protection against cancer) could be explained by the presence of the following nutritional components:

1. Olive oil (monoenic fatty acids - MUFA, squalene and phenolic compounds)

2. Fish oil (n-3 polyunsaturated fatty acids)

3. Fruits and vegetables (natural antioxidants - bioflavonoids, ascorbic acid, soluble and insoluble dietary fibre and phytosterols)

Diet high in oleic acid, n-3 PUFA, lipid soluble antioxidants (alfa tocopherol, squalene) and low in cholesterol and saturated fats (SFA) may provide a plausible explanation for the apparent benefit of the diet (Tab. 2, 3). 
Tab. 2: Content of PUFA in vegetable oil and fish oil (g fatty acids per $100 \mathrm{~g}$ total fatty acids).

\begin{tabular}{|c|c|c|c|c|c|c|c|c|c|c|}
\hline & $\begin{array}{c}\text { Fatty } \\
\text { acid } \\
\text { source }\end{array}$ & Palmitic & $\begin{array}{l}\text { Palmito- } \\
\text { leic }\end{array}$ & Stearic & Oleic & Linoleic & Linolenic & $\begin{array}{c}\text { Arachi- } \\
\text { donic }\end{array}$ & $\begin{array}{c}\text { Eicosa- } \\
\text { pentae- } \\
\text { noic }\end{array}$ & $\begin{array}{c}\text { Docosa- } \\
\text { hexae- } \\
\text { noic }\end{array}$ \\
\hline \multirow{3}{*}{ vegetable } & Olive & 11.8 & 0.9 & 2.8 & 74.5 & 8.7 & 1.0 & - & - & - \\
\hline & Palm & 45.1 & - & 4.8 & 36.8 & 10.2 & 0.5 & - & - & - \\
\hline & Sunflower & 6.6 & 0.1 & 4.3 & 22.4 & 65.2 & 0.3 & - & - & - \\
\hline \multirow{4}{*}{ fish } & Herring & 0.4 & 18.3 & 2.2 & 16.9 & 1.6 & 0.6 & 0.4 & 8.6 & 7.6 \\
\hline & Mackerel & 0.5 & 28.2 & 3.9 & 19.3 & 1.1 & 1.3 & 3.9 & 7.1 & 10.8 \\
\hline & Salmon & - & 15.3 & 3.8 & 27.2 & 1.5 & 0.9 & 0.5 & 3.4 & 2.5 \\
\hline & Tunny & 0.6 & 22.1 & 6.1 & 21.7 & 2.1 & 1.2 & 3.0 & 13.2 & 17.3 \\
\hline
\end{tabular}

Tab. 3: Nutritional composition of Mediterranean diet (fat) (modified from Willet WC. Mediterraneat diet pyramid: a cultural model for healthy eating. Am J Clin Nutr 1995; 61:1402-1406).

\begin{tabular}{|c|c|}
\hline Nutrients intake & Mediterranean diet \\
\hline Total fat & $33-40 \%$ of energy \\
\hline Saturated & $\leq 8 \%$ of energy \\
\hline MUFA & $16-29 \%$ of energy \\
\hline Source of MUFA & $(60-80 \%$ from olive oil $)$ \\
\hline PUFA & $\leq 7 \%$ of energy \\
\hline
\end{tabular}

\section{Monoenic fatty acids (oleic fatty acid) in the Mediterranenan diet}

Approximately $90 \%$ of monounsaturated fatty acids (MUFA) present in this dietary pattern is cis-form of oleic acid (cis 18:1) and a major part of it comes from olive oil.

MUFA enriched diet low in saturated fatty acids (SFA) have a pleiotropic effect in the prevention of cardiovascular diseases:

\section{Diets rich in MUFA and blood pressure}

A positive relationship has been found between blood pressure and a high intake of SFA, alcohol and salt, whereas dietary intervention trials showed a significant decrease of blood pressure by $9 \%$ in individuals consuming the Mediterranean diet - 38\% total fat, 22\% MUFA $(2,11,13)$.

2. Role of dietary monounsaturated fats (olive oil) in etiopathogenesis of atherosclerosis

Oxidative modification of low density lipoproteins (LDL), endothelial dysfunction and dietary lipids, particularly PUFA may modulate the development of atherosclerosis affecting the structure and function of arterial wall. Dietary fat determines plasma LDL concentration and the susceptibility to oxidative modification (10). The changes caused by the diet in the PUFA and MUFA content in LDL and the availability of antioxidants in plasma can modulate the formation of modified LDL deposited in atheromatous plaques via macrophages scavenger receptors.

Lipoproteins rich in MUFA show less oxidability in comparison to the LDL particles enriched by $n-6$ PUFA and according to some studies also LDL particles enriched by n-3 PUFA. High levels of alfa tocopherol do not suppress enhanced oxidation of LDL enriched by n-6 PUFA $(1,15)$.

Some findings suggest that LDL rich in monosaturated fatty acids when exposed to oxidative stress caused less monocyte chemotaxis ( $52 \%$ decrease), lower monocyte adhesion (77\% decrease) and suppressed significantly proinflammatory effect (15).

Consumption of the Mediterranean type diet rich in MUFA and antioxidants could protect arterial endothelium, improve endothelial dysfunction and restore endotheliumdependent vasodilatation to normal (3).

\section{Dietary MUFA and carbohydrate metabolism}

The development of polymetabolic syndrom and type 2 diabetes mellitus is related to overeating, high intake of mono-, disaccharides and saturated fats. High intake of simple and complex carbohydrates had a negative metabolic effect on obese and diabetic patients. A diet based on high carbohydrate consumption could give rise to triacylglycerol synthesis and very low density lipoprotein plasma level. The accumulation of triacylglycerols in the muscles suppresses muscle insulin sensitivity, deteriorates hyperlipoproteinaemias and lowers plasma levels of high density lipoproteins.

The reduction of SFA and carbohydrates in the diet and replacing SFA by MUFA results in the decrease of both postprandial plasma glucose and insulin concentrations, lowers peak postprandial glucose level and decreases 24hours glucose urinary excretion (7).

\section{Possible role of squalene in the Mediterranean diet}

Squalene, an isoprenoid compound similar to beta carotene is intermediate metabolite in the cholesterol synthesis. In tissues, squalene appears to be a quencher of singlet oxygen and indispensable precursor in dolichol and ubiquinone synthesis (Coenzyme Q 10).

Many polyprenyl compounds similar to squalene, performing critical metabolic functions are found in the nature including vitamin $\mathrm{A}$, vitamin $\mathrm{K}$, tocopherols, dolichols etc. 
Squalene received its name because of its occurrence in shark liver oil. Reasonable amounts of squalene in plants are found only in olive oil (1\%) and amaranth oil (7\%). In humans, $60 \%$ of dietary squalene is absorbed and transported by lipoproteins to the tissues. In lipid metabolism squalene reduces cholesterol and triacylglycerol plasma concentrations in hyperlipemic individuals (5).

Rao at al. (12) assessed squalene chemopreventive efficiency on colonic abberant crypt foci. The diet containing $1 \%$ of squalene in fat inhibited abberant crypt formation by about $46 \%$, suggesting chemopreventive activity against colon carcinogenesis.

\section{Phenolic components with antioxidant properties in the Mediterranean diet: protective effect against coronary heart disease and cancer}

It has been postulated that the lower incidence of coronary heart disease and prostatic and colon cancer in the Mediterranean region is due to the influence of numerous nutritional factors. Olive oil as a source of 30 phenolic compounds exerts strong antioxidant properties. The major phenolic compounds in olive oil are tyrosol, hydroxytyrosol and oleuropein (16). High consumption of virgin olive oil, particularly rich in these phenolic antioxidants as well as in oleic acid and squalene provides protection against coronary heart disease, against colon cancer and exerts the inhibition of oxidative stress (8).

\section{Health promoting effect of n-3 PUFA}

Epidemiological and clinical trials with fish oils (eicosapentaenoic acid, docosahexaenoic acid) have demonstrated a significant effect in the prevention of cardiovascular diseases (4). Several mechanisms explain the cardioprotective effect of n-3 PUFAs, including hypolipidemic, antiarrhytmic, anti-inflammatory and antithrombotic. Eicosapentaenoic acid inhibits the synthesis of thromboxane A2, an eicosanoid which causes increased platelet aggregation, platelet adhesion and vasoconstriction (table 4).

Tab. 4: Effect of n-3 and n-6 PUFA (modified from Manner T, Askanazi J. Fish oils and lung. Clin Nutr 1993; 12: 131-146).

\begin{tabular}{|l|c|c|}
\hline & $\begin{array}{c}\mathrm{n}-3 \\
\text { PGI3, } \\
\text { TXA3 }\end{array}$ & $\begin{array}{c}\mathrm{n}-6 \\
\text { PGE2, } \\
\text { TXA2 }\end{array}$ \\
\hline Platelet aggregation & $\Downarrow$ & $\Uparrow \Uparrow$ \\
\hline Pulmonary vasoconstriction & $\Downarrow$ & $\Uparrow$ \\
\hline Blood viscosity & $\Downarrow$ & \pm \\
\hline Membrane fluidity & $\Uparrow$ & $\Downarrow$ \\
\hline Vascular permeability & \pm & $\Uparrow \Uparrow$ \\
\hline Cancer cachexia & $\Downarrow$ & $?$ \\
\hline
\end{tabular}

(PGI - prostaglandin, TXA- tromboxane)
The consumption of at least 1-2 fish meals per week reduced the risk of sudden cardiac death by $52 \%(p=0.03)$ compared with the subjects consuming fish only once a month (4).

Endothelial dysfunction is corrected by n-3 PUFA because eicosapentaenoic and docosahexaenoic acids enhance the vasodilatory effect of nitrous oxide (NO) and reduce the endothelial expression of vascular cell adhesion molecules and leukocyte binding to the endothelium (17). The effect of n-3 PUFA is predominantly antiatherogenic and reduces also the complications of atherosclerosis in the secondary prevention (antithrombotic and anti-inflammatory effect in stabilization of atherosclerotic plaque).

Fish oil in the diet has a significant effect in reducing total plasma cholesterol and plasma triacylglycerols in hyperlipidemic patients. Unlike some vegetable oils (sunflower oil) rich in n-6 PUFAs, fish oil containing predominantly n-3 PUFAs does not lower high density lipoproteins (HDL) (Table 4).

\section{Cholesterol lowering effect of phytosterols}

Western population ingests only a small amount of plant sterols like sitosterol, campesterol and stigmasterol (approximately $250 \mathrm{mg}$ per day). Vegetable oils and vegetables are rich sources of plant sterols, which are poorly absorbed from the gastrointestinal tract. The Mediterranean population ingests about 2.5-3 g or even more of plant sterols, but the absorption is only 5-10 mg per day. Phytosterols or phytostanols intake over $2 \mathrm{~g}$ per day decreases effectively cholesterol absorption from gut, reduces plasma cholesterol by around $10 \%$, LDL cholesterol by $10-15 \%$, with minimal change in HDL cholesterol and does not cause malabsorption (14).

\section{Conclusion}

The high intake of MUFA in the Mediterranean diet results in multiple health benefits including the improvement of insulin resistance in type 2 diabetics and in patients with polymetabolic syndrome, the decrease of atherogenic lipoproteins in plasma and a reduction in LDL oxidizability.

Substantial evidence suggests that oleic acid enriched LDL is more resistant to oxidative modification, the reduction of oxidized LDL in plasma improves endothelial dysfunction, endothelium dependent vasodilatation and lowers the adhesion of monocytes to the endothelial surface.

Squalene and phenolic compounds present in olive oil have shown considerable protection against coronary heart disease and probably chemopreventive effect in prostatic cancer and colon cancer.

The evidence from randomized clinical trials suggests a daily dose of 750-1000 mg of n-3 PUFAs in the primary or secondary prevention of coronary heart disease.

This dose should be consumed in two or more fish meals per week. 
The content of phytosterols in vegetable oil and vegetables (sitosterol, stigmasterol, campesterol etc.) suppresses cholesterol absorption from the gastrointestinal tract. A daily intake of 2-3 g of phytosterols in the diet could lower total cholesterol in hypercholesterolemic patients by $8-10 \%$.

\section{Acknowledgment}

Supported by grant IGA MZ CR NB 7589-3.

\section{References}

1. Baroni S, Amelio M, Sangiorgi Z. Solid monounsaturated diet lowers LDL unsaturation trait and oxidizability in hypercholesterolemic (type IIb) patients. Free Rad Res 1990; 30:275-285.

2. Espino A, López-Miranda J, Castro P. Monounsaturated fatty acid enriched diets lower plasma insulin levels and blood pressure in healthy young men. Nutr Met Cardiovasc Dis 1996; 6:147-154.

3. Harrison DG, Armstrong ML, Freiman PC. Restoration of endothelium-dependent relaxation by dietary treatment of atherosclerosis. J Clin Invest 1987; 80:1808-1811.

4. Hyrper ChR, Jacobson TA. The Fats of Life. The Role of Omega-3 Fatty Acids in the Prevention of Coronary Heart Disease. Arch Intern Med 2001; 161:2185-92.

5. Kelly GS. Squalene And Its Potential Clinical Uses. Altern Med Rev 1999; 4:29-36.

6. Lorgeril M, de Salen P, Paillard F. Mediterranean diet and the French paradox: Two distinct biogeographic concepts for one consolidated scientific theory on the role of nutrition in coronary heart disease. Cardiovascular Res 2002; 54:503-15.

7. National Institute of Health. Concensus development conference on diet and exercise in non-insulin-dependent diabetes mellitus. Diabetes Care 1987; 10:639-644.

8. Owen RW, Giacosa A, Hull WE. Olive-oil consumption and health: the possible role of antioxidants. The Lancet Oncology 2000; 1:107-112.

9. Panagiotakos DB, Chrysohoou Ch, Pitsavos Ch. The association of Mediterranean diet with lower risk of acute coronary syndromes in hypertensive subjects. Internat J Cardiol 2002; 82:141-7.
10. Partharasathy S, Khoo JO, Miller E. Low density lipoprotein rich in oleic acid is protected against oxidative modification: implications for dietary prevention of atherosclerosis. Proc Natl Acad Sci USA 1990; 87:3894-3988.

11. Péréz-Jiménez F, López-Miranda J, Mata P. Protective effect of dietary monounsaturated fat on arteriosclerosis: beyond cholesterol. Atherosclerosis 2002; 163:385-98.

12. Rao CV, Newmark HL, Reddy BS. Chemopreventive effect of squalene on colon cancer. Carcinogenesis 1998; 19:287-1103.

13. Salas J, López-Miranda J, Jansen S. La dieta rica en grasa monoinsaturada modifica de forma beneficiosa el metabolismo de los hidratos de carbono y la tensión arterial. Med Clin (Barc) 1999; 113:765-9.

14. Simons LA. Diet and blood cholesterol. Role of Plant Sterol-Enriched Spreads. Curr Therapeutics 1999; 40:11-13.

15. Tsimikas S, Philis-Tsimikas A, Alexopoulos S. LDL isolated from Greek subjects on a typical diet or from American subjects on an oleate-supplemented diet induces less monocyte chemotaxis and adhesion when exposed to oxidative stress. Arterioscler Thromb Vasc Biol 1999; 19:122-130.

16. Tuck KL, Hayball PJ. Major phenolic compounds in olive oil: metabolism and health effects. J Nutrit Biochem 2002; 13:636-644.

17. Vogel RA, Corretti MC, Plotnick GD. The Postprandial Effect of Components of the Mediterranean Diet on Endothelial Function. J American College Cardiol 2000; 36:1455-1460

Submitted January 2006.

Accepted January 2006.

Prof. Zdeněk Zadák, MD, PhD, University Hospital in Hradec Králové, Department of Gerontology and Metabolic Care, Sokolská 581,

Hradec Králové, Czech Republic. e-mail: zadak@lfhk.cuni.cz 